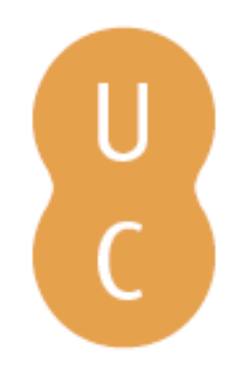

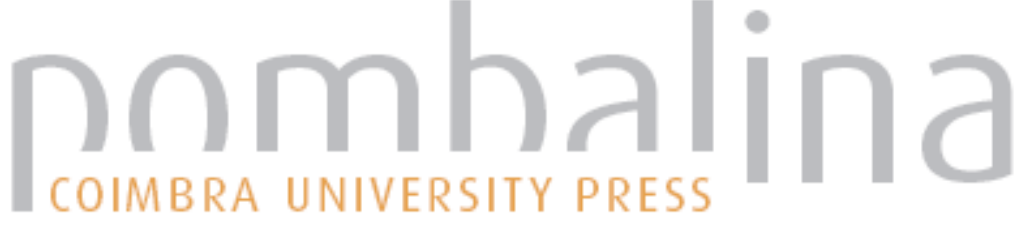

\section{A Física na Reforma Pombalina da Universidade de Coimbra}

Autor(es): $\quad$ Ruivo, Maria da Conceição

Publicado por: Imprensa da Universidade de Coimbra

URL

persistente: URI:http://hdl.handle.net/10316.2/32256

DOI: $\quad$ DOI:http://dx.doi.org/10.14195/978-989-26-0413-8_3

Accessed : $\quad$ 26-Apr-2023 15:10:37

A navegação consulta e descarregamento dos títulos inseridos nas Bibliotecas Digitais UC Digitalis, UC Pombalina e UC Impactum, pressupõem a aceitação plena e sem reservas dos Termos e Condições de Uso destas Bibliotecas Digitais, disponíveis em https://digitalis.uc.pt/pt-pt/termos.

Conforme exposto nos referidos Termos e Condições de Uso, o descarregamento de títulos de acesso restrito requer uma licença válida de autorização devendo o utilizador aceder ao(s) documento(s) a partir de um endereço de IP da instituição detentora da supramencionada licença.

Ao utilizador é apenas permitido o descarregamento para uso pessoal, pelo que o emprego do(s) título(s) descarregado(s) para outro fim, designadamente comercial, carece de autorização do respetivo autor ou editor da obra.

Na medida em que todas as obras da UC Digitalis se encontram protegidas pelo Código do Direito de Autor e Direitos Conexos e demais legislação aplicável, toda a cópia, parcial ou total, deste documento, nos casos em que é legalmente admitida, deverá conter ou fazer-se acompanhar por este aviso. 
João Rui Pita

Coordenaçáo

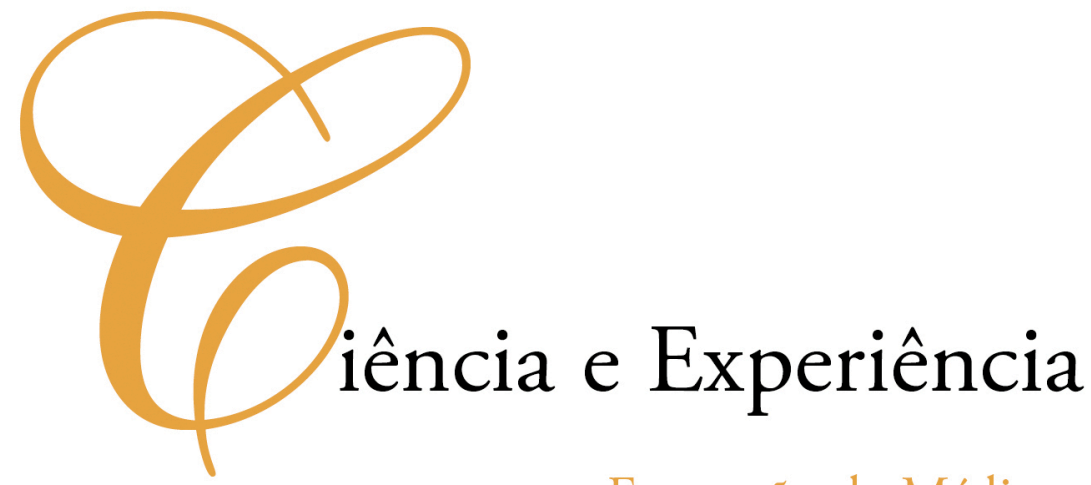

Formação de Médicos, Boticários, Naturalistas e Matemáticos

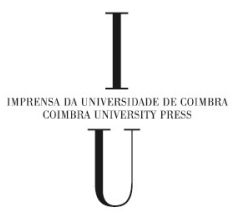

- COIMBRA 2006 
Maria da Conceição Ruivo

Departamento de Física

Faculdade de Ciências e Tecnologia da Universidade de Coimbra

\title{
A física na reforma pombalina da \\ UNIVERSIDADE DE COIMBRA
}

\author{
Estou aqui construindo o novo dia \\ com uma expressão tão branda e descuidada \\ que dir-se-ia \\ não estar fazendo nada. \\ E, contudo, estou aqui construindo o novo dia. \\ Porque o dia constrói-se; não se espera. \\ Não é sol que deflagre num improviso de luz. \\ É um orfeão de vozes surdas, um arfar de troncos nus, \\ o erguer, a uma só voz, dos remos da galera. \\ Cantando entre dentes \\ um refrão anidro \\ abro linhas quentes \\ com um escopro de vidro. \\ Abro linhas quentes \\ sem tremer a mão, \\ com um escopro de vidro \\ de alta precisão.
}

António Gedeão, Poesias Completas

\section{Ciência e Iluminismo}

Assim cantava o poeta António Gedeão; assim poderíamos começar a falar da obra do homem de ciência, do pedagogo Rómulo de Carvalho. Se existe actualmente, cada vez mais nítida, a consciência de que conhe- 
cer as raízes históricas da ciência que hoje praticamos é condição para melhor a sabermos projectar no futuro, então a obra do grande mestre é uma lição sobre o futuro. Uma lição construída com sobriedade e rigor, com «um escopro de vidro de alta precisão». O período setecentista e, em particular, a reforma pombalina da Universidade de Coimbra, foi um dos grandes objectos do labor científico de Rómulo de Carvalho. O que vos trago aqui hoje é uma breve reflexão, que tem como referência principal a obra de Rómulo de Carvalho, sobre esse período da história da ciência em Portugal, em que o sopro da modernidade que nos chegava da Europa se defrontava com mentalidades e estruturas ultrapassadas, procurando abrir novos caminhos.

Falar na ciência do século XVIII, pressupõe naturalmente recuar até à grande revolução científica que tem o seu apogeu no século XVII, o século de Galileu, Kepler, Descartes, Boyle, Huygens e Newton. No entanto, uma revolução científica não se esgota nos grandes nomes e não se cumpre num intervalo de tempo restrito. Para que o conteúdo dos conceitos e teorias inovadores seja clarificado e apreendido, e dele se tirem todas as consequências, até se constituir um paradigma científico, é necessário um longo percurso de maturação. O século XVIII é esse tempo de consolidação e aprofundamento da revolução galilaico-newtoniana, um tempo onde o novo e o velho ainda por vezes se digladiam.

A nova ciência emergente no século XVII é uma ciência da medida: do mundo das qualidades e dos elementos de Aristóteles, passa-se para um universo onde tudo se explica em termos de matéria e forças, um universo que funciona como um mecanismo de relógio e onde tudo evolui de forma previsível e determinada. Os fenómenos físicos são descritos em linguagem matemática, a linguagem por excelência em que, segundo Galileu, está escrito o grande livro do universo. A experiência passa a ser a ferramenta privilegiada para interrogar a natureza e para validar o conhecimento. O mundo dos sábios vai encontrar-se com o das artes e ofícios e criar as técnicas. A ciência passa a ser seriamente encarada como um poderoso agente de transformação social. 
Não foi por acaso que o confronto entre as novas e as velhas ideias se centrou essencialmente no domínio da ciência do movimento, e que a mecânica foi o primeiro ramo do saber a desenvolver-se, tornando-se na mais "exacta» das ciências. Assim, a filosofia mecanicista, onde, a pouco e pouco, o cartesianismo perde terreno a favor do newtonianismo, irá dominar todo o século da Luzes. É neste século que, graças aos trabalhos de Lagrange, D’Alembert, Euler e Bernoulli, a mecânica fica alicerçada em sólidas bases matemáticas, tornando-se assim o ramo do conhecimento mais organizado; que se fundam os alicerces da mecânica dos fluidos; que, no quadro conceptual e formal da obra de Newton, Coulomb estabelece os princípios básicos da electrostática e da magnetostática. Outros ramos do saber terão que esperar pelo século XIX para atingirem a sua maturidade, e os problemas que lhes dizem respeito são, frequentemente, objecto de viva discussão: é o caso da natureza da luz, onde continuam a defrontar-se as teorias corpuscular de Newton e ondulatória de Huygens, da natureza do calor, da estrutura da matéria, onde o debate sobre o atomismo continua na ordem do dia, da incomodidade das interacções a distância.

Concomitantemente ao surgimento de novos conceitos e novos métodos, as práticas científicas e pedagógicas sofreram profundas alterações. A ciência passou a ser encarada como um grande empreendimento colectivo. O papel dia a dia mais importante desempenhado pelas Academias, a criação de revistas científicas, são disso um sinal. No século XVIII, o ensino da Física torna-se indissociável duma base fortemente experimental. À nova pedagogia estão associados os nomes de grandes divulgadores, como Nollet, Muschenbroek, 's Gravesande, Desagullier, Sigaud de la Fond. Paralelamente, desenvolve-se a indústria de fabricação de instrumentos científicos, construídos com o requinte e a arte que são característicos do espírito da época. O interesse pelas novas ciências extravasa a comunidade científica, as sessões de divulgação públicas tornam-se moda por toda a Europa, nas Academias e Universidades, mas também nos salões da aristocracia. A ciência passa a ser objecto das preocupações intelectuais de um círculo dia a dia mais amplo. 


\section{A situação em Portugal: o legado do ensino dos jesuítas e as primeiras vozes dissonantes}

Que se passava entretanto em Portugal? Até meados do século XVIII, e desde meados do século XVI, o ensino esteve essencialmente nas mãos dos jesuítas. Tratava-se de um ensino conforme às tradições aristotélico-tomistas, apesar do declínio do escolasticismo já vir de longe. Note-se que, já no século XV, o grande Nicolau de Cusa afirmava a propósito do movimento da Terra:

Os antigos não chegaram às verdades que ora expusemos porque não atingiram a "douta ignorância». A partir de agora é claro em toda a sua verdade que a Terra se move, ainda que não pareça, porque só somos capazes de compreender o movimento em relação a algo de fixo.

Em Portugal, em 1746, José Veloso, Reitor do Colégio da Artes determinava, em edital afixado à entrada do Colégio, que:

[...] nos exames, ou Liçoes, Concluzoes publicas ou particulares se-não insine defenção ou opinioes novas pouco recebidas, ou inuteis p. ${ }^{a}$ o estudo das Sciencias mayores como sao as de Renato Descartes, Gacendo, Neptono, e outros, e nomeadate qualquer Sciencia, q defenda os actos [átomos] de Epicuro, ou negue as realid. ${ }^{\text {es }}$ dos accidentes Eucharisticos, ou outras quaisquer concluzois oppostas ao sistema de Aristoteles, o qual nestas escólas se deve seguir, como repetidas vezes se recomeda nos Estatutos deste Collegio das Artes.

No entanto, os jesuítas estavam em dia com as «opiniões novas pouco recebidas", que contestavam com conhecimento de causa. Aos poucos, tinham surgido membros da comunidade jesuíta que se inclinaram demasiado para tais opiniões, como é o caso de Inácio Monteiro e de Manuel de Campos. A simpatia de Inácio Monteiro pela Filosofia Natural dos Modernos valeu-lhe uma repreensão do Geral da Ordem, em 1752. No entanto, dois anos depois, este autor publica um Compêndio de Elementos de Mathematica onde 
defende as ideias dos Modernos, nomeadamente o recurso à experiência e ao cálculo matemático para estudar os fenómenos naturais, afirmando:

A Physica verdadeira que nestes tempos se cultiva, não são os entes da razão, as possibilidades e chymeras dos antigos, ociosas subtilezas do entendimento humano. Estudamos hoje a natureza pela observação, e pelo cálculo; os entes da razão não se medem pela Geometria; porém esta sciencia he o fundamento dos conhecimentos physicos, que fazem o corpo da Philosofia moderna.

Para Inácio Monteiro «a Physica experimental é tão agradável, que não suporta o método escolástico e todo esse fastidioso aparato de silogismos». O mesmo espírito de abertura anima o seu contemporâneo Manuel de Campos, professor de Matemática no Colégio de Santo Antão, que publica dois compêndios de Matemática: Elementos de Geometria plana e sólida segundo a ordem de Euclides (1735) e Trigonometria Plana e Esférica (1737), escritos em Português, o que era novidade na época. Nestas obras, as demonstrações de Geometria, considerada então como indispensável para o estudo da Física, eram, como declara o autor, apresentadas segundo o "método dos Modernos».

O meio intelectual português começou, antes de meados do século, a receber a influência das ideias novas por outras vias. Diversos intelectuais tinham frequentado as cortes europeias, onde tinham estado em contacto com as novidades e vieram a tornar-se agentes de uma transformação de mentalidades, que, embora restrita a uma elite, viria a dar os seus frutos. São os denominados "estrangeirados", entre os quais se contam homens de ciência e de letras, políticos, médicos, engenheiros. É o caso do diplomata Luís da Cunha, do conde de Ericeira, Francisco Xavier de Meneses, e do seu círculo de amigos, onde se contam nomes como Rafael Bluteau, Manuel de Azevedo Fortes, Manuel Caetano de Sousa, Manuel Serra Pimentel, Luís Caetano de Lima. As Academias, que tinham começado a surgir em Portu- 
gal em Seiscentos, são centros de reunião e discussão, onde se divulgam e cimentam as novas ideias. De entre elas, a Academia Real de História Portugueza, fundada em 1720, e constituída principalmente por elementos do círculo dos ericeirenses, desempenha um papel de vulto na difusão do saber, através de diversas obras publicadas pelos seus membros. A propósito dos modelos do universo, convirá aqui citar um pequeno excerto da obra do académico Luís Caetano de Lima, Geografia Histórica de todos os Estados Soberanos da Europa, publicada em 1734. No capitulo IX, Dos Systemas mais Principaes, o autor apresenta os sistemas de Ptolomeu, Copérnico e Tycho Brahe, segundo a fórmula clássica de apresentação do sistema e argumentos pró e contra. No primeiro argumento contra o sistema de Copérnico, escreve o autor:

I. Argum. por parte da authoridade. Todo o Systema contrario à Escritura Sagrada naõ se pode defender: sed sic est, que o Systema de Copernico he contrario à Escritura Sagrada: logo o Systema de Copernico se naõ pode defender. Responde-se distinguindo a mayor: todo o Systema contrario à Escritura Sagrada naõ se pode defender, como Systema, e como verdade, concedo: como hypothese, ou supposiçaõ nego. Deste modo se responde Catholicamente a este argumento, conservando hum inteiro repeito à Sagrada Escritura, às decisoens da Igreja, e às interpretaçoens dos Santos Padres. Mas porque se naõ ignorem os caminhos, por onde os Copernicanos se pertendem defender, individuaremos mais os argumentos, que se lhe fazem com a Escritura, e apontaremos a suas pertendidas respostas.

O que se segue é uma defesa discreta do modelo de Copérnico, a que Caetano de Lima dedica mais do dobro das páginas do que aos outros dois modelos.

Um dos Modernos que maior influência exerceu nesta primeira metade de século, foi Luís António Verney, autor do Verdadeiro Método de Estudar (1746). O conteúdo da sua obra, e a forma incisiva de exprimir as suas ideias, são a fonte da grande polémica que o envolveu. Verney é um gran- 
de defensor da Física Experimental, atacando vivamente os Peripatéticos: «Tanto sabe um puro Peripatético dos efeitos naturais como sabe um cego de cores: ambos falam do que não viram, um porque não tem olhos outro porque os não quer ter.» Outro nome ilustre é o de Ribeiro Sanches, discípulo de Boerhaave na Universidade de Leyden, médico de Catarina da Rússia, autor de diversas obras de medicina e do livro Cartas sobre a Educação da Mocidade (1760). Embora o seu interesse principal fosse, naturalmente, a Medicina, Ribeiro Sanches dedica a sua atenção a diversos aspectos da educação e, no que respeita à Física (geral e experimental), realça a sua importância como elemento curricular de base:

Não somente os Medicos necessitaõ possuir esta Sciencia da Physica geral, mas taõbem todos aquelles que se applicam às Sciencias e às Artes. A Náutica, a Architectura, Arte Militar, a Jurisprudencia Civil e Politica tem os seus principais fundamentos nesta Sciencia: alem disso necessitamos della em quase todas as occurrencias da vida.

A sua posição moderna em relação ao ensino desta matéria manifesta-se, por exemplo, nos livros que recomenda para o seu estudo: Elementa Physicae de Peter van Muschenbroek e Recreação Philosofica de Teodoro de Almeida.

Jacob de Castro Sarmento, médico cristão-novo radicado em Londres, é considerado um dos primeiros divulgadores do newtonianismo em Portugal. Em 1737, publica uma versão da obra de Newton sobre a teoria das marés, Theorica verdadeira das mares, conforme à Philosofia do incomparavel cavalhero Isaac Newton. Na dedicatória desta obra a Manuel de Ataíde e Sousa, podemos surpreender o vivo empenhamento de Castro Sarmento na modernização do ensino em Portugal à luz da "Philosophia Experimental» de Newton:

A sua [ de Newton ] Philosophia Experimental, e demonstrativa, armada da verdade, e força Geometrica, tem entrado, Senhor, por toda a Europa, menos Portugal e Espanha, sem encontrar a menor resistencia; e 
como a preocupaçam com que os nossos Portuguezes retem geralmente as Ideas de Aristoteles, e alguns as de Des Cartes, sam hum gravissimo impedimento para se difundir esta grande luz nesse Reyno, levado da glória dessa Naçam, e Patria minha, e do natural impulso, com que V. E. ama a Mathemática, escrevi este Commento a preposito, pelo Methodo mais claro, e evidente, para que chegasse a todos huma Idéa deste Philosopho Ilustre, pois pelo dedo se conhece o Gigante, e para que V. E. concorra [ ... ] para a introducçam da verdadeira Philosophia Natural nesse Reyno.

Finalmente, não podemos deixar de mencionar, ainda que brevemente, João Jacinto de Magalhães, cientista, construtor de instrumentos, divulgador, membro das principais Academias científicas do seu tempo.

Uma outra corrente de modernização do meio intelectual português é de origem clerical e diz respeito à actividade dos oratorianos. Os oratorianos eram Modernos, no entanto eram também em boa parte aristotélicos, embora a sua interpretação de Aristóteles fosse diferente da dos jesuítas. Um oratoriano, o padre João Batista, publica mesmo uma obra onde tenta conciliar a sua leitura de Aristóteles com as concepções da ciência moderna, a Philosophia Aristotelica Restituta. Os oratorianos foram instalados no tempo de D. João V, na Casa das Necessidades, onde dispunham de excelentes meios para desenvolver a sua actividade. Seguindo a moda na Europa, desde cedo se dedicam à realização de sessões de divulgação de Física Experimental, que, ao que consta, eram frequentadas pela própria realeza. Um dos discípulos do padre João Batista vai exceder em envergadura o seu mestre e tornar-se num dos vultos mais interessantes da nossa cultura científica neste século. Trata-se de Teodoro de Almeida, autor, entre outras obras, da célebre Recreação Filosófica, obra em dez volumes publicada entre 1751 e 1880. Embora Teodoro de Almeida nem sempre delimite convenientemente os campos da Física e da Filosofia, podemos encontrar na sua obra, elaborada à maneira clássica do diálogo entre três amigos com concepções diferentes, exposições de grande clareza e modernidade. O 
mestre oratoriano é um notável pedagogo e um grande defensor da Física Experimental, tendo-se dedicado, no bem apetrechado Gabinete de Física da Casa das Necessidades, a diversas experiências. Vítima da perseguição do marquês de Pombal, acaba por se refugiar em Baiona, só regressando ao país no reinado de D. Maria.

Pelo que se acaba de expor, vemos que a necessidade de uma mudança era sentida nos mais variados quadrantes, o terreno estava preparado para uma profunda reforma no sistema de ensino português.

\section{A Física na reforma pombalina da Universidade de Coimbra}

Após a subida ao trono de D. José, em 1750, o ministro do Reino, Sebastião José de Carvalho e Melo, toma em mãos a reforma do ensino no país. Nas cortes de Viena e Londres, o então conde de Oeiras tinha ficado a par das novas ideias e forjara um projecto ambicioso de reforma, não hesitando em recorrer a meios violentos para o executar. A expulsão dos jesuítas, a contratação de professores estrangeiros, a aquisição de modernos equipamentos, são algumas das medidas do marquês de Pombal com vista a pôr de pé um sistema de ensino com conteúdos e metodologias modernas. Infelizmente, os ódios do marquês levaram-no a perseguir intelectuais de grande valor, jesuítas ou não, que teriam tido um papel importante na reforma. Veja-se o caso de Teodoro de Almeida. A fundação do Colégio dos Nobres, em 1761, é o primeiro ensaio de introdução do ensino de disciplinas científicas segundo as novas metodologias. Tendo-se saldado este projecto por um fracasso, Carvalho e Melo tira dele os ensinamentos que lhe vão permitir atacar em melhores condições a reforma dos estudos na Universidade de Coimbra. Para o efeito cria a Junta de Providência Literária, que, em 1771, elabora um relatório sobre o estado de coisas na Universidade, o Compêndio bistórico do estado da Universidade de Coimbra no tempo da 
invasão dos denominados Jesuítas, e dos estragos feito nas ciências e nos professores e directores que a regiam, pelas maquinações dos novos estatutos por eles fabricados. Os estatutos pombalinos estão prontos em Fevereiro de 1772 e as aulas começam em Novembro do mesmo ano. Uma das inovações da reforma iluminista é a criação de duas novas faculdades, a de Matemática e a de Filosofia (esta última vinha substituir a extinta «miserável Faculdade das Artes») e, uma vez que o novo ensino se queria experimental, são adstritos ao sistemas de Faculdades novos estabelecimentos científicos, a saber: Teatro Anatómico, Jardim Botânico, Museu de História Natural, Gabinete de Física Experimental, Laboratório Químico e Dispensário Farmacêutico.

Que trazem de inovador os Estatutos pombalinos no que se refere à Física? Irão cumprir-se os ambiciosos projectos, ou o peso de antigas estruturas continuará a fazer-se sentir? Que o tempo de elaboração do projecto de reforma foi curto, tendo em vista os objectivos pretendidos, parece evidente, pelo menos no que toca às disciplinas científicas. Efectivamente, constando os Estatutos de três volumes, só o terceiro é dedicado às novas faculdades e, além disso, inclui também a de Medicina. No que concerne à Física, esperar-se-ia a criação, senão de um curso autónomo, pelo menos de um conjunto de disciplinas que formassem um todo coerente, mas o que acontece é a criação de duas cadeiras de Física dispersas em duas faculdades diferentes, a de Filosofia e a de Matemática. Do curso filosófico, consta, no terceiro ano, a cadeira de Física Experimental. A Física, embora já não seja um mero capítulo da Filosofia, essencialmente especulativo e retórico, como no tempo dos jesuítas, continua a estar subordinada à Filosofia. Trata-se de um curso relativamente elementar, que era também frequentado por alunos de outras Faculdades, nomeadamente a de Matemática. Pressupõe-se que o aluno de Filosofia deve dispor de um mínimo de bases matemáticas, que vai adquirir frequentando cadeiras do primeiro ano do curso de Matemática, com especial destaque para a Geometria. Por seu turno, do terceiro ano do Curso Matemático consta a cadeira de Foronomia, a ciência do movimento, onde tem lugar um estudo mais elaborado da Física, com recurso ao cálculo diferencial. 
Analisemos as disposições dos Estatutos em relação à disciplina de Física Experimental. Os estudantes filósofos, tendo frequentado antes as cadeiras de História Natural e de Geometria Elementar, estariam em condições de ser iniciados numa disciplina em que a experiência é a pedra de toque:

[ ....a experiência] que he huma observação mais subtil, procurada por artíficio para descobrir o véo da Natureza; e para lhe perguntar os segredos mais reconditos das suas operações, quando ella por si mesma não fala.

Prossegue depois o legislador expondo em linhas gerais os objectivos desta cadeira. Grande ênfase era posta na necessidade de fazer com que o estudante assimilasse, pela prática, os princípios do método experimental, tanto do ponto de vista conceptual como de execução, "como se requer nos exploradores da Natureza».

[...] e dará uma idéa geral da sagacidade, e attenções, que se devem aplicar na Arte de fazer Experiencias, como se hão de repetir, e combinar; como se hão de distinguir os factos accessórios dos principaes, como se hão-de distribuir os effeitos complicados de huma Experencia, por meio de outras experiencias parciaes, que excluem sucessivamente as circunstancias da primeira, e como se deve fazer uso da razão; para se conjecturar o efeito antes de o experimentar; e para se escolherem as circumstâncias, em que se devem fazer experiencias decisivas, e izentas de toda a equivocação.

Adverte-se o Professor de todas as cautelas que deve ter ao ministrar o ensino desta disciplina. Por exemplo, não deve entrar demasiado no domínio das explicações físico- matemáticas, nem «cahir naquelle furor de explicar tudo, que Descartes introduziu na Fysica», o que não exclui o uso sagaz e ponderado da conjectura e da analogia. Deve ainda evitar os assuntos escuros, como, por exemplo, a natureza das forças ou a natureza da luz. O programa preconizado trataria em geral dos tópicos que eram de uso nos manuais da época. Começaria pelas propriedades gerais da matéria, 
seguindo-se-lhe a mecânica, onde se trataria da gravidade, do movimento, das máquinas simples e compostas, das forças centrais. Seguir-se-ia o estudo das propriedades dos fluidos, e recomendava-se nomeadamente: «Também explicará as propriedades do $\operatorname{Ar}[$... ] Depois disto explicará as da Agua [ ... ] e do mesmo modo tratará do Fogo». O uso desta terminologia e compartimentação aristotélicas, que aliás também vemos aparecer em bons manuais setecentistas, põe em evidência que, em domínios do saber menos organizados, a coexistência do novo com o velho persiste, apesar da revolução científica. Finalmente, vem o estudo da luz, o do magnetismo e o da electrostática. Os Estatutos recomendavam ainda que os professores escrevessem os seus próprios compêndios, em Latim. Este é mais um dos aspectos conservadores da reforma iluminista dos finais do século XVIII em Portugal, a determinação de que o Latim continuasse a ser a língua do saber erudito.

Como foi posta em acção esta reforma? Aquando da criação do Colégio dos Nobres, o marquês de Pombal tinha-o dotado de um excelente Gabinete de Física Experimental, que, na sua opinião, era "O melhor de todos que tem hoje a Europa» e tinha contratado para o ensino da Física o professor italiano Giovanni Antonio dalla Bella. Extinto o ensino das ciências no Colégio dos Nobres, o marquês transferiu para Coimbra o professor dalla Bella e todo o material do Gabinete.

Do material existente neste período dão-nos conta os inventários de dalla Bella. O primeiro inventário, o Index Instrumentorum de 1778, descreve minuciosamente 580 "máquinas», indicando o local da sua arrumação no Gabinete e incluindo citações de autores da época onde material do mesmo tipo se encontra descrito. O Index impresso de 1790 regista 592 máquinas (das doze máquinas adquiridas fazem parte a máquina de Atwood, a balança santoriana, e material de electricidade). Trata-se efectivamente de uma notável colecção de instrumentos, construídos com «engenho e arte».

Sabe-se que os trabalhos de madeira foram executados por um artífice português, Joaquim José dos Reis, segundo os modelos dos grandes manuais 
da época. As peças de metal provêm, de um modo geral, da Real Fabrica de Lisboa, do industrial genovês Schiapa Pietra, à época estabelecido em Portugal. Outros instrumentos, para os quais se exigia mão de obra sofisticada de que Portugal não dispunha, foram adquiridos no estrangeiro, principalmente em Inglaterra. Construtores famosos, como George Adams, Culpeper, e Nairne assinam algumas das peças do Gabinete.

Do ponto de vista científico e didáctico, podemos distinguir instrumentos que dizem respeito a problemas fundamentais, como é o caso das propriedades da matéria, da gravidade, do movimento, dos fenómenos eléctricos e magnéticos; outros são de aplicação tecnológica, como é o caso de máquinas simples e compostas. A maior parte dos instrumentos tem em vista a realização de experiências com a mera finalidade de demonstração ou de ilustração dos princípios físicos, e não de investigação. Note-se que algumas destas experiências são, aos nossos olhos, um tanto ingénuas, como por exemplo as que dizem respeito às propriedades da matéria, e têm um carácter meramente qualitativo. Nalguns instrumentos prevalece mesmo o carácter lúdico e espectacular, como é o caso do belíssimo centauro de prata. Existem, no entanto, alguns instrumentos concebidos com finalidade de realizar experiências "izentas de toda a equivocação». A máquina de Atwood, para o estudo das leis da queda dos graves, adquirida no final do século, e da qual faz parte uma pêndula da autoria de João Jacinto de Magalhães, é, porventura, um dos instrumentos que melhor permite cumprir esse objectivo.

No Index de 1788 os instrumentos estão agrupados por 22 tópicos científicos (mais 2 de utensílios e de material omitido). Esses tópicos são, de um modo geral, os preconizados nos Estatutos. O grosso da colecção diz respeito, como seria de esperar, à mecânica seguida do ar e da óptica. No entanto, todos os outros tópicos da Física cultivados no século XVIII são contemplados. É curioso notar que, no Index Instrumentorum, os tópicos que se seguem às propriedades da matéria são, um pouco inesperadamente, 
a atracção (onde se tratam fenómenos como, por exemplo, a capilaridade) e o magnetismo, seguindo-se o estudo da mecânica, que se inicia com a gravidade. A electricidade é o último tópico. Sabe-se que no século XVIII o mistério das interacções a distância era objecto de apaixonada polémica e o estabelecimento das afinidades entre elas nem sempre foi claro. Esta posição do magnetismo será fruto de simples coincidência ou reflexo tardio da discussão sobre a natureza das diferentes forças? No entanto, o Lente de Física Experimental dedicou-se à investigação do magnetismo, procurando, inclusivamente, estabelecer experimentalmente a lei das acções magnéticas. No compêndio de Física de sua autoria, o magnetismo já aparece depois da electricidade e é incluído mesmo um tópico sobre a analogia entre fenómenos eléctricos e magnéticos. A contribuição mais importante do século XVIII no campo da Física é o desenvolvimento da electrostática. Na colecção de Coimbra encontramos um conjunto representativo de instrumentos desta área, embora comparativamente reduzido, se atendermos à grande importância do tema na época. Não encontramos uma balança de Coulomb, embora a lei de Coulomb tenha sido publicada em 1785 e dalla Bella lhe faça referência no seu compêndio.

O compêndio de Física de dalla Bella, o Physices Elementa, publicado em 3 volumes, entre 1789 e 1790, vem substituir, como texto base do curso, o compêndio de Musschenbroek, que tinha sido provisoriamente adoptado. $\mathrm{O}$ professor demorou bastantes anos a dar cumprimento ao estabelecido nos Estatutos, que, como já referimos, determinava que os professores escrevessem os seus próprios manuais. Na opinião de alguns, trata-se de um livro prolixo e desactualizado em relação ao seu tempo; Rómulo de Carvalho considera-o, no entanto, de nível aceitável, embora modesto, comparado com os dos seus contemporâneos estrangeiros. Nalguns aspectos, o autor mostra-se em consonância com as ideias de vanguarda, como, por exemplo, quando prefere o modelo de Franklin ao de Nollet para explicar os fenómenos eléctricos; noutros, mostra-se retrógrado, como quando defende a concepção de Descartes para avaliar «a força que anima os corpos em movimento», por oposição à de Leibniz. 
Devido ao seu interesse, convém fazer aqui um pequeno parêntesis sobre este problema, que, aliás, já datava do século XVII mas continuava na ordem do dia no século XVIII, e de cuja importância nos dá conta um instrumento da colecção pombalina que chegou aos nossos dias: a balança de Mersenne. No problema em questão, o que estava em causa era efectivamente o conceito de energia e não o de força. O conceito de energia, no entanto, é um conceito abstracto, que pressupõe um estádio bastante desenvolvido da Física e que, de facto, só é claramente formulado no século XIX. O termo "força» era por muitos usado nos séculos XVII e XVIII com sentidos diversos: força, velocidade, energia, quantidade de movimento. Dizia-se que os corpos em movimento adquiriam uma "força" (nós hoje diríamos energia) e tratava-se de encontrar uma grandeza operacional que desse conta dessa "força». Leibniz define-a adequadamente por uma expressão matemática que hoje identificamos com uma forma particular de energia, a energia cinética, ao contrário de Descartes, que a definia como quantidade de movimento. O Padre Mersenne, o fundador da Academia das Ciências Francesa e adepto de Descartes, concebeu um instrumento cuja finalidade era decidir pela experiência entre Descartes e Leibniz. Infelizmente, não se tratava de um instrumento que permitisse fazer um experiência "limpa», era inevitável um grande erro experimental. Este problema deu lugar a uma apaixonada polémica, que dividiu nomes ilustres da época. Utilizada pelos cartesianos, a balança do padre Mersenne confirmava a sua teoria, mas, nas mãos dos seguidores de Leibniz, dava razão a este. Um exemplo interessante de como, nos períodos em que está em embrião um novo conceito e nem os instrumentos teóricos nem os experimentais estão convenientemente forjados, a função da experiência não é a de fornecer uma resposta objectiva e concludente, mas sim a de obrigar a equacionar problemas que só se podem resolver pela articulação entre teoria e experiência. No final do século XVIII, o método de Leibniz já reunia a maior parte dos consensos; no entanto, dalla Bella continuava a ensinar que ele estava totalmente errado. Uma posição que contrasta com a do mestre oratoriano Teodoro de Almeida. 
Finalmente, é importante referir que o Gabinete de Física estava magnificamente apetrechado do ponto de vista bibliográfico. De facto, chegou felizmente aos nossos dias uma excelente biblioteca, onde estão representados todos os grandes tratadistas da época.

Não obstante as críticas que possam ser feitas ao projecto de ensino da Física na reforma pombalina, é inquestionável que a criação do Real Gabinete de Física e a ênfase colocada na prática experimental representam um marco da maior importância na história da Física no nosso país. Uma das funções do ensino das ciências é precisamente modificar as nossas intuições e torná-las operacionais. Ora, a Física newtoniana é em boa parte contra-intuitiva; para a sua assimilação é essencial, e isto tanto no passado como nos nossos dias, uma pedagogia baseada na experiência. O próprio carácter lúdico e espectacular de algumas demonstrações tem a sua função pedagógica. Do entusiasmo dos estudantes do século XVIII pelas experiências de Física dá-nos conta o Reitor D. Francisco de Lemos, em carta ao marquês onde relata a primeira aula experimental dada pelo professor dalla Bella.

Dou parte a V. Exa que sabado 22 do corrente se abrio pela primeira vez o Theatro das Experiencias, q interinam ${ }^{\text {te }}$ se fez na Sala do $\mathrm{Col}^{\mathrm{O}}$ real das Artes, concorrendo a este insolito, e novo espectaculo huma

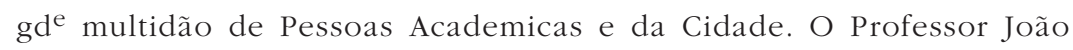
Antonio Dolabela principiou por uma elegante Dissertaçaõ sobre a

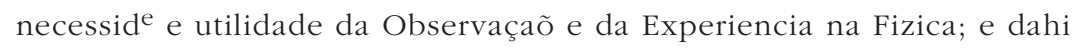
passou a fazer experiencias da Divisibilidade da Materia, que tinha sido o assunto das Liçoens da semana; o que tudo executou com gde gosto, e aplauzo do Auditorio. Sabado se hão-de continuar as experiencias, que serão as da Impenetrabilide e da Figurabilidade. Esta abertura produzio um tal fogo, e ardor na Mocide, que eu não sei dignamente reprezentar a V. Ex ${ }^{\mathrm{a}}$.

Numa altura em que tanto nos preocupa o insucesso escolar na Física, não podemos deixar de sonhar com o dia em que os nossos alunos disponham nas suas escolas de laboratórios que não os levem a invejar a sorte dos estudantes setecentistas. 


\section{BIBLIOGRAFIA}

AlmeIDA, Teodoro de, Recreação Philosofica, 10 vol., Lisboa, 1751-1800.

Carvalho, Rómulo de, História do Gabinete de Física da Universidade de Coimbra, desde a sua fundação (1772) até ao jubiléu do professor italiano Giovanni Antonio dalla Bella, Universidade de Coimbra, Biblioteca Geral, Coimbra, 1978.

Carvalho, Rómulo de, A Física Experimental em Portugal no Século XVIII, Instituto da Cultura e Língua Portuguesa, Lisboa, 1982.

CARvalho, Rómulo de, "A Física na Reforma Pombalina", História e Desenvolvimento da Ciência em Portugal, Vol. I, Publicações do II Centenário da Academia das Ciências de Lisboa, Lisboa, 1986, pp. 143-165. (Reproduzido em O Engenho e a Arte, Colecção de Instrumentos do Real Gabinete de Física, Universidade de Coimbra/Fundação Calouste Gulbenkian, Coimbra, 1997, pp. 33-51.

CARVAlHO, Rómulo de, "A pretensa descoberta da lei da acções magnéticas por dalla Bella, em 1781, na Universidade de Coimbra», Revista Filosófica, Ano IV, n 11, Coimbra, 1954, pp. 103-138.

GEDEÃo, António, Poesias Completas, Portugalia Editora, Lisboa, 1968.

LimA, Luiz Caetano de, Geografia Historica de todos os Estados Soberanos da Europa, Academia Real da Historia Portugueza, Lisboa, 1734.

PROVIDÊnCIA, João da, "Física Experimental e Física da Quantidade», O Engenho e a Arte, Colecção de Instrumentos do Real Gabinete de Física, Universidade de Coimbra/Fundação Calouste Gulbenkian, Coimbra, 1997, pp. 21-25.

PROVIDÊNCIA, João da, "O Museu Pombalino de Física e a Reforma Pombalina”, Colóquio Ciências, $\mathrm{n}^{\circ} 19$, Lisboa, 1997, pp. 55-68.

SANCHES, António Nunes Ribeiro, Obras, Vol. I, Universidade de Coimbra, Coimbra, 1959.

SARMENTO, Jacob de Castro, Theorica verdadeira das mares, conforme à Philosofia do incomparavel cavalbero Isaac Newton, Londres, 1737.

Silva, Mário A. "O Museu Pombalino de Física da Faculdade de Ciências de Coimbra", Seara Nova, $\mathrm{n}^{\circ}$ 1414, 1963, pp. 199-201. (Reproduzido em O Engenho e a Arte, Colecção de Instrumentos do Real Gabinete de Física, Universidade de Coimbra/Fundação Calouste Gulbenkian, Coimbra, 1997, pp. 33-51).

Estatutos da Universidade de Coimbra (1972) Livro III, Universidade de Coimbra, Coimbra, 1972.

O Engenho e a Arte, Colecção de Instrumentos do Real Gabinete de Física, Universidade de Coimbra/Fundação Calouste Gulbenkian, Coimbra, 1997.

Les Mechanismes du Génie, Instruments Scientifiques du XVIII et XIX ${ }^{e}$ Siecles, Ed. Robert de Smet, Europalia 91, Charleroi, 1991. 